\title{
Musculoskeletal injuries related to the practice of the shuttlecock game
}

\begin{abstract}
During three important Brazilian championships, in the years of 2005 and 2006, this study evaluated 96 shuttlecock players in order to identify the epidemiology of the musculoskeletal lesions and to correlate them to the sporting activities of these elite athletes. Of those interviewed $81,25 \%$ suffered from different types of injuries, among which 188 affections were found. Tendinitis, that mainly affects shoulders and knees, was the most common cause of eliminating athletes $(30,85 \%)$. All athletes, who were interviewed, mentioned pain in the volar face of the hands during the first weeks in contact with the shuttlecock. Statistically, there was no significant difference between sex and the occurrence of injuries. On the other hand, this study showed that the longer the time of practice, the greater the probability of shuttlecock-related lesions $(\mathrm{p}<0,05)$. The conclusions are: tendinitis, which was the most common cause of injury; pain in the volar face of the hands, which was mentioned by all of the athletes; and, the longer the time of practice, the greater the probability of shuttlecock related lesions.
\end{abstract}

Volume 2 Issue I - 2018

Leandro Gomide

Hospital Orthomedcenter, Brazil

Correspondence: Leandro Gomide, Hospital Orthomedcenter, Brazil,Tel 5534984|24847,

Email leandro@orthomedcenter.com.br

Received: September 27, 2017 | Published: January 10, 2018

Keywords: Tendinitis, athletic injuries, epidemiology, retrospectives studies

\section{Introduction}

The shuttlecock is a playful object of Indian origin that is widespread in Brazilian popular culture. Records are that the natives have played the game of shuttlecock, with objects made of straw, since before the discovery of Brazil. The shuttlecock, first of all, is a recreation object. Built in many ways, it has kept a common structure since its origin: a base with vertically arranged feathers on it. Minas Gerais was the pioneer State in the development of the shuttlecock game, giving the official form to its object and the competitive sense to the game.

In 1985, due to the growth of this sport, it was officially and legally necessary to codify its rules in order to avoid doubts in its interpretation and to ensure uniformity in its practice. According to Brazilian Confederation of Shuttlecock, since 1988 the shuttlecock game has grown in several other Brazilian States and expanded abroad as well, being now practiced in Bolivia, Chile, Uruguay, the United States, France, Portugal, the Netherlands, Switzerland, Denmark, Russia, Estonia, Japan and South Africa.

The shuttlecock game does not impose age limits and neither requires a high cost to start. Unlike most indoor sports, such as volleyball, basketball, handball and indoor soccer, the shuttlecock game needs far fewer athletes to start the game. It takes at least two players, as the court is smaller. It is a simple sport that avoids the use of accessories, such as the badminton racket. It uses only one hand to touch the shuttlecock, which can be done "from below" or "from above ", and that is related to the shoulder level. Promoting health and the relishing that sport provides, the demand for the shuttlecock game rose even more, not only as a form of recreation, but also for competitive purposes. To achieve those levels, it is necessary for 'players to have a very high training load, including resistance training, agility, and strength, because if it is incorrectly and /or excessively performed, it may lead to overuse injuries, in addition to those inherent to the sports practice .

\section{Goals}

Due to the rapid growth of the sport in the last two decades and the deficiency, or even the absence of data on injuries in the practice of the shuttlecock game, this study is aimed to identify the epidemiology of musculoskeletal injuries reported by the athletes during the practice this sport.

\section{Materials and methods}

During three important national competitions, in 2005 and 2006, ninety- six athletes considered elite of the shuttlecock game from eight clubs in Brazil were evaluated. The interviews were conducted by orthopaedic surgeons from Hospital Orthomedcenter of Uberlândia/ MG. Data collection took place, generally, before the start of each competition, through prior contact with coaches and athletes. After agreeing to participate in the study, the subjects signed a consent form authorizing the use of data that would be collected. Respondents answered a questionnaire, with the accompaniment of the researcher, who provided information and clarified doubts at the time of the responses. This questionnaire contained several questions on: athlete data, sports practice time, pain and bruising on their hands in the early days of contact with the shuttlecock, the injuries occurred (presence, type and location) due to the practice of the sport in question. It took each athlete no more than ten minutes to answer all questions. This is a descriptive study, approved by the Research Ethics Committee of the Hospital Orthomedcenter. Only adult athletes were evaluated, category (21-30 years old).

The diagnoses were divided according to Brynnhildsen et al. ${ }^{1}$ work on bruises, fractures and dislocations, sprains, muscle injuries and tendinitis. Lesions were characterized when having caused at least one day of absence from sports, according to McLennan et al., ${ }^{2}$ and when they were diagnosed by an orthopedic surgeon and by clinical examination and imaging, in order to have accurate information about the real name of the injury. Some data were statistically analyzed ${ }^{3,4}$ 
in order to check a possible correlation of the lesion variable with sports practice time, for which the Spearman Correlation Coefficient Stations were used; and to correlate lesions with sex, we used the Chisquared test as well

\section{Results}

The average age of respondents was 29.4 years (ranging from 2040 years), being $54(56.25 \%)$ of them male individuals. Figure 1 shows the percentage of athletes, by sex, practicing the sport. We evaluated 96 athletes; 78 (81.25\%) reported some type of injury resulting from the shuttle, 40 men (41.6\%) and 38 women (39.6\%); the remaining 18 (18.8\%) reported no injury. As shown in Figure 2, 188 injuries were recorded, being tendinitis the most frequent one, with 58 citations $(30.85 \%)$, followed by sprains with $52(27.66 \%)$, muscle injury with $46(24.47 \%)$, of bruises (athlete trauma) with 28 references $(14.89 \%)$, and fractures with citations $4(2.13 \%)$. Tendinitis was especially more common in the shoulders and knees, with 27 and 17 citations respectively, as shown in Figure 3. Sprains occurred more in ankles, with 41 citations $(78.8 \%)$ and the remaining 11 citations (20.2\%) in the knee. Muscle injuries were most common in the thigh with 25 citations, followed calf with 15 , back only 5 citations and only one in the abdomen. Figure 4 shows the main types of lesions.

\section{Figure 1}

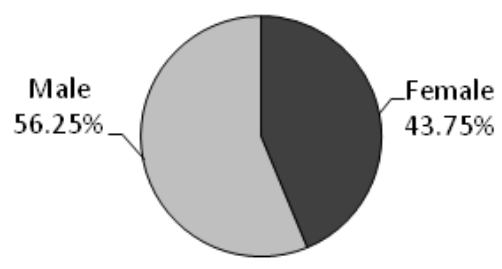

Figure I Distribution of athletes in relation to sex.

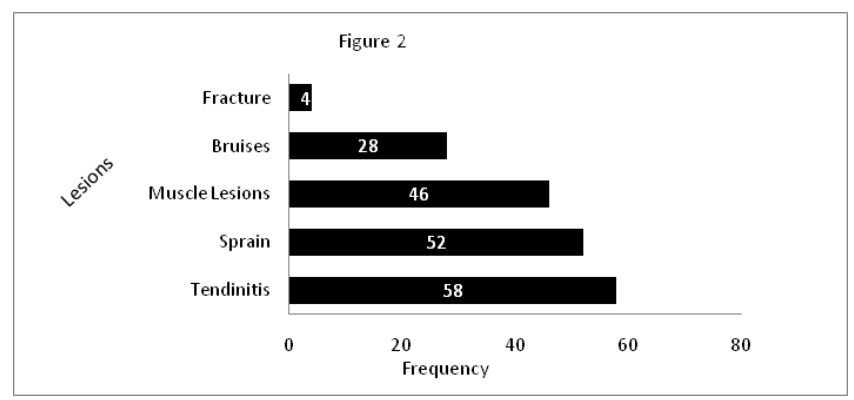

Figure 2 Distribution of results in relation to injuries.

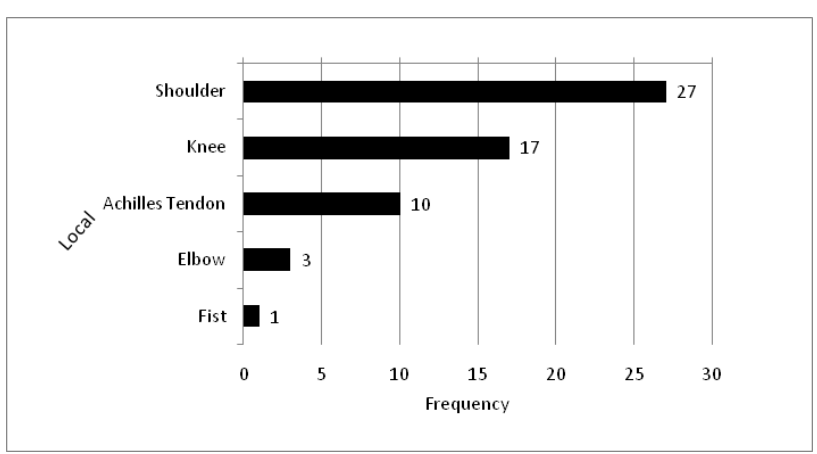

Figure 3 Distribution of results regarding the location of tendinitis.

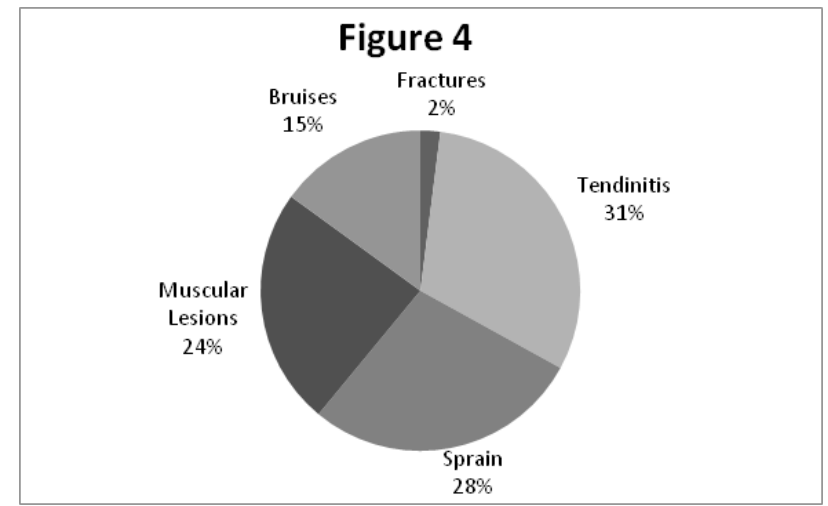

Figure 4 Main types de lesions.

There were two foot fractures (metatarsal) and two in the ankle. The most often affected joint by injury was the ankle $(26.2 \%)$, followed by the shoulder $(18.4 \%)$, and the knee $(16.9 \%)$. It is interesting to report that $100 \%$ of the athletes mentioned pain in their hands due to contact (touch) with the shuttle in the early days of training and $89.7 \%$ reported bruise in the volar part of the hand. The average time of sports practice was 5.9 years, with a minimum of two and maximum of 20 years. Regarding the analysis, there is no statistically significant correlation between gender and lesions $(\mathrm{p}>0.05)$. Since the correlation between injuries and the shuttlecock practice time, we observed that there is a statistically significant difference $(p<0.05)$, i.e: the time of this sport contributes to the occurrence of injuries.

\section{Discussion}

The need for agility and speed, direction changes, acceleration and slowing down, as well as cut mechanism are the main factors that cause injuries. It is worth mentioning that the shuttlecock game is not a contact sport. The most frequently reported conditions were tendinitis that is also what happens in table tennis. ${ }^{5}$ Shoulders were the most frequently affected part of the body and it is believed that it is due to the movement of touching "over". In volleyball, according to Aagaard \& Briner, et al. ${ }^{6,7}$ tendinitis mostly affects the knee. Interestingly, the third most affected place by tendinitis was the Achilles tendon as shown in Figure 3, which is also a very affected segment in badminton. ${ }^{8,9}$ Sprains showed up in the lower limbs, as well as those that happen in table tennis players. Perhaps this is due to the large amount of lateral displacements required by these. We always suggest the use of specific floors for this sport, as well as the use of appropriate footwear and ankle orthoses, such as Briner et al. ${ }^{7}$ do.

We also found many muscular injuries. We related this number to the fact that it is a sport that uses a lot of impulse and this is similar to the injuries shown by great speed athletics. ${ }^{10,11}$ We found few fractures, being all of them in the foot and the ankle. The respondents reported that they were caused by twisting mechanism, not by traumas. In badminton, Hoy et al. ${ }^{12}$ found $5 \%$ of fractures. Regarding the location of the lesions, we found that they predominately occur in the lower limbs (76.8\%), similarly to sports that involve rackets. ${ }^{8,13}$ About pain in the hands of $100 \%$ of the interviewed athletes, they stated that it generally disappears after an average of two weeks of practice, and that is due to the improvement of the touch, that makes it more deadened. They also reported that the pain sensation is due to the shuttlecock base material which is made of overlapping layers of 
rubber. $78 \%$ of them say that pain usually comes on again, fading after some minutes, during the cold months. We confirmed our suspicion that the longer this sport is practiced, the greater is the possibility of injury, which was statistically verified $(\mathrm{p}<0.05)$. The shuttlecock game is being increasingly practiced, but there are no studies that demonstrate the epidemiology of injuries. We believe that only with a better understanding of their epidemiology, one can assure better prevention and thus increase the efficiency of this sport.

\section{Conclusion}

Among the injuries reported by the athletes, the most frequent was tendinitis. All athletes had pain in the volar part of their hands due the touch on the shuttlecock. Greater duration of activity, the greater will be likelihood of lesions $(\mathrm{p}<0.05)$.

\section{Acknowledgements}

None.

\section{Conflict of interest}

Author declares that there is no conflict of interest.

\section{References}

1. Brynhildsen J, Ekstrand J, Jeppsson A, et al. Previous injuries and persisting Symptoms in female soccer players. Int J Sports Med. 1990;11(6):489-492

2. McLennan JG, McLennan JE. Injury patterns in Scottish heavy athletes. Am J Sports Med. 1990;18(5):529-532.
3. Siegel S. Non-parametric statistics for the behavior sciences. Brazil: McGraw-Hill; 1975.

4. Morettin P, Bussab W. Basic Statistics. São Paulo Current. 1987.

5. Petri FC, Rodrigues RC, Cohen M, et al. Muscle injuries - skeletal related to the practice of table tennis. Rev Bras Ortop. 2002;37(8):358-362.

6. Aagaard H, Jørgensen U. Injuries in elite volleyball. Scand J Med Sci Sports. 1996;6(4):228-232.

7. Briner WW, Kacmar L. Common injuries in volleyball. Mechanisms of injury, prevention and rehabilitation. Sports Med Chicago. 1997;24(1):65-71.

8. Fahlström M, Lorentzon R, Alfredson H. Painful conditions in the Achilles tendon region: a common problem in middle-aged competitive badminton players. Knee Surg Sports Traumatol Arthrosc. 2002;10(1):57-60.

9. Fahlström M, Björnstig U, Lorentzon R. Acute badminton injuries. Scand J Med Sci Sports. 1998;8(3):145-148.

10. Laurino CFS, Lopes AD, Mano KS, et al. Lesões músculo-esqueléticas no atletismo. Rev Bras Ortop São Paulo. 2000;35(9):364-368.

11. Lysholm J, Wiklander J. Injuries in runners. Am J Sports Med. 1987;15(2):168-171.

12. Høy K, Lindblad BE, Terkelsen CJ, et al. Badminton injuries: a prospective epidemiological and socioeconomical study. $\mathrm{Br} J$ Sports Med. 1994;28(4):276-279.

13. Chard MD, Lachmann SM. Racquet Sports-Patterns of Injury presenting to a sports injury clinic. Br J Sports Med. 1987;21(4):150-153. 